\title{
The Effects of Smoking Ban in Closed Public Spaces on the Status of Smoking
}

\author{
Selda Tekiner ${ }^{1}$, Tuğba Yurdakul ${ }^{2}$, Gülsen Ceyhun Peker ${ }^{1}$ and Mehmet Ungan ${ }^{1}$ \\ 1. Department of Family Medicine, School of Medicine, University of Ankara, Ankara 06100, Turkey \\ 2. Republic of Turkey Ministry of Health, Iğneada Family Health Center, Demirköy Kırklareli 39650, Turkey
}

\begin{abstract}
Smoking Ban in Closed Public Spaces went into effect in Turkey on May 19, 2008. We aimed at investigating the status of smoking among hospital staff following the ban. The study was conducted with the staff of the university hospital other than physicians. A questionnaire form investigating the status of smoking among hospital staff, the effects of the ban on smoking in closed public spaces, their thoughts that might affect their decisions to quit smoking or to decrease the number of cigarettes smoked was implemented. Prior to each interview, the participants read and signed the informed consent form. Mean and percentage distributions were used in the evaluation of the data. Of 60 individuals, $68 \%$ were female, mean age was $40.72 \pm 7.25$. Of them $50 \%$ were active smokers. After the ban $55 \%$ of the smokers declared a decrease in the number of cigarettes they smoked, $37 \%$ said no change. The ban had no effect on smokers' decisions about quitting smoking. Social leadership and role model characteristics of healthcare professionals should be taken into consideration and the habit of smoking should be handled as a disease, and medical approaches including behavioral therapy should be given the necessary significance they deserve.
\end{abstract}

Key words: Cigarette smoking, smoking ban, effect, smoking cessation, medical staff.

\section{Introduction}

Tobacco use is a significant and preventable public health issue. While 5 million people die due to direct tobacco use each year in low- or medium-income countries in the world, $80 \%$ of the mortality cases are related to tobacco use [1]. World Health Organization (WHO) estimates that the yearly mortality rate related to tobacco use will exceed 8 million until the year 2030 and this figure will account for $10 \%$ of all mortality cases in the world [2]. The prevalence of tobacco use and smoking between the ages of 13 and 15 in Turkey is $16.8 \%$ and $10.4 \%$ respectively, while the same values are $27.1 \%$ and $26.9 \%$ for individuals older than 15 years of age [3]. To address the global burden of tobacco, The World Health Assembly in 2003 unanimously adopted the World Health Organization Framework Convention on Tobacco Control (FCTC).

Corresponding author: Selda Tekiner, assistant professor, research fields: women health, adolescent health, smoking and substance use disorders, violence.
In force since 2005, the main objective of WHO FCTC is to protect present and future generations from the devastating health, social, environmental, and economic consequences of tobacco consumption and exposure. "Framework Convention on Tobacco Control," which is the first international treaty on tobacco control, was adopted by the 56th World Health Assembly of WHO on May 21, 2003 in Geneva and was signed by the Turkish Republic's Ministry of Health on April 28, 2004. The Turkish Ministry of Health has developed a "National Tobacco Control Programme" covering the years 2006 to 2010 in order to facilitate the planning of studies within the scope of "Framework Convention on Tobacco Control" and to protect citizens, especially the young, by controlling tobacco consumption. Pursuant to this program, amendments, changes, and regulations were carried out in Article 4207, which was adopted in November 1996 and has been in effect since, and each individual's right to breathe clean air was safeguarded. The regulation underlined the fact that not only smokers but also 
future generations should be protected from the hazardous health effects of cigarettes and similar tobacco products. Accordingly, "Smoking Ban in Closed Public Spaces" went into effect in Turkey on May 19, 2008 [4].

Healthcare providers assume an important role as leaders in their societies and are both motivators and role models for all sections of the society for the prevention of smoking initiation $[5,6]$. In this context, we aimed at investigating the status of smoking among hospital staff following the "Ban on Smoking in Closed Public Spaces" (BSCPS).

\section{Materials and Methods}

This study is a descriptive, questionnaire-based study. The study was conducted by Ankara University Medical School's Department of Family Medicine with the staff of the same university hospital other than physicians. A questionnaire form investigating the status of the habit of smoking among hospital staff was developed by the researchers. The questionnaire, which had a total of 15 questions with 3 being open-ended and the rest close-ended, included the identifying characteristics of the participants (age, sex, level of education, profession), their status of smoking, the effects of the ban on smoking in closed public spaces for them, and their thoughts that might affect their decisions to quit smoking or to decrease the number of cigarettes smoked.

The participants were informed about the aim of the study before filling out the questionnaire and a signed consent stating that they accepted to be a participant of the study was obtained. The questionnaire forms were filled through the face-to-face interview method. Prior to each interview, the participants read the informed consent form and were informed about the study; voluntary participation was the norm. Completion of the whole questionnaire lasted for about 5-10 min.

The analyses were performed using Statistical Package for the Social Sciences (SPSS) 11,0.

Mean and percentage distributions were used in the evaluation of the data collected within the scope of the study.

\section{Results and Analysis}

83 individuals were contacted during the study while 60 of these individuals consented to participate in the study and filled out the questionnaire. $68 \%$ of the participants were female while $32 \%$ were male with a mean age of $40.72 \pm 7.25$.

$50 \%$ of the participants were active smokers. The remaining 32\% had never smoked in their lives, while $18 \%$ had smoked for a time but quit smoking. The participants' statuses of smoking are shown in Table 1.

$15 \%$ of the participants who had smoked before and quit smoking and of those who were active smokers stated that they started smoking before they were 15 years of age, while $20 \%$ stated that they started smoking after they were 21 years of age (Table 2).

While the most common reason for starting smoking was stated to be having a smoker friend (56\%), it was followed by curiosity (29\%), imitation (29\%), and having smoking individuals in the family (15\%) (Table 3).

The mean age of the $18 \%$ who had smoked for a period in their lives and quit was $35.15 \pm 9.71 .64 \%$ of these individuals quit smoking before the BSCPS, while $36 \%$ quit after the ban. The most common reason to stop smoking was related to health issues $(72 \%)$ and followed by familial requests $(36 \%)$, financial reasons (27\%), friends' pressure and willing to set a good example for inner circle. There were no participants stating that they had quit smoking because of the ban and/or legal sanctions.

When we asked the active smoker participants whether there had been a change in the number of cigarettes they smoked after the BSCPS, $55.0 \%$ declared a decrease, $37 \%$ said no change, and $7 \%$ mentioned an increase.

When we asked the active smokers whether the BSCPS had any impact on their consideration of quitting smoking, 55\% said it had no impact while 44\% stated that they became more eager to quit smoking. 
Table 1 Statutes of smoking according to age, gender, education, occupation.

\begin{tabular}{llll}
\hline & Never smoked & Quit smoking & Active smoker \\
\hline Age & & & \\
\hline Mean \pm S.D. & $37.5 \pm 5.3$ & $46 \pm 6.1$ & $\begin{array}{l}39.5 \pm 5.8 \\
\mathrm{n}(\%)\end{array}$ \\
\hline Gender & $\mathrm{n}(\%)$ & & $21(35.0)$ \\
\hline Female & $14(23.3)$ & $6(10.0)$ & $9(15.0)$ \\
Male & $5(8.3)$ & $5(8.3)$ & $1(1.6)$ \\
\hline Education & & & $11(18.3)$ \\
\hline Primary school & $0(0)$ & $0(0)$ & $11(18.3)$ \\
College & $6(10.0)$ & $1(1.6)$ & $7(11.6)$ \\
High school & $8(13.3)$ & $5(8.3)$ & $3(5.0)$ \\
University & $5(8.3)$ & $5(8.3)$ & $5(8.3)$ \\
\hline Occupation & & & $10(16.6)$ \\
Secretary & $1(1.6)$ & $0(0.0)$ & $4(6.4)$ \\
Laboratorian & $8(13.3)$ & $3(5.0)$ & $8(13.3)$ \\
Nurse & $8(13.3)$ & $3(5.0)$ & $30(50.0)$ \\
Data processor & $2(3.3)$ & $0(0.0)$ & \\
Technician & $0(0)$ & $5(8.3)$ & $11(18.3)$ \\
TOTAL & $19(31.6)$ & & \\
\hline
\end{tabular}

Table 2 Smoking initiation age of those who had quit and those who are active smokers.

\begin{tabular}{lllll}
\hline \multirow{2}{*}{ Smoking initiation age } & \multicolumn{3}{c}{ Smoked and quit before } & \multicolumn{2}{c}{ Active smokers } \\
\cline { 2 - 5 } & $\mathrm{n}$ & $\%$ & $\mathrm{n}$ & $\%$ \\
\hline$<15$ & 4 & 9.7 & 2 & 4.8 \\
$15-16$ & 0 & 0 & 9 & 21.9 \\
$17-18$ & 2 & 4.8 & 9 & 21.9 \\
$19-20$ & 2 & 4.8 & 4 & 9.7 \\
21 & 2 & 4.8 & 6 & 14.6 \\
\hline
\end{tabular}

Table 3 The reasons for smoking initiation for active smokers and/or those who had quit smoking.

\begin{tabular}{lll}
\hline Reasons & $\mathrm{n}$ & $\%$ \\
\hline Having a smoker friend & 23 & 56.1 \\
Curiosity & 12 & 29.2 \\
Imitation & 12 & 29.1 \\
Having smoking individuals in the family & 6 & 14.6 \\
Stress & 6 & 14.6 \\
Social influence & 4 & 9.6 \\
Prove oneself & 1 & 2.4 \\
Effects of cigarette advertisements & 1 & 2.4 \\
\hline
\end{tabular}

The mean figure for those in this group with regards to their eagerness to stop smoking over 10 was $5.2 \pm 2$.

The ban on advertising for tobacco products had a strong impact on $18.1 \%$ of the participants with regards to quitting smoking while $81.7 \%$ was not affected by the ban. Warnings on cigarette packs had an impact on $18.2 \%$ of the participants with regards to quitting smoking but they had no effect on $73 \%$. When the participants were asked whether price measures taken, namely increases in the prices, had any impact on quitting smoking 9.1\% said they were effective, while $81.7 \%$ stated that they had no impact (Table 4).

The ban on advertising for tobacco products had an impact on $13.2 \%$ of the participants with regards to 
Table 4 Factors effecting in quitting smoking.

\begin{tabular}{|c|c|c|c|c|c|c|}
\hline & \multicolumn{2}{|c|}{$\begin{array}{l}\text { The ban on advertising for } \\
\text { tobacco products }\end{array}$} & \multicolumn{2}{|c|}{ Warnings on cigarette packs } & \multicolumn{2}{|c|}{ Namely increases in the prices } \\
\hline & $\mathrm{n}$ & $\%$ & $\mathrm{n}$ & $\%$ & $\mathrm{n}$ & $\%$ \\
\hline Absolutely disagree & 6 & 54.5 & 6 & 54.5 & 3 & 27.2 \\
\hline I disagree & 3 & 27.2 & 2 & 18.1 & 6 & 54.5 \\
\hline I have no idea & 0 & 0 & 1 & 9.1 & 1 & 9.1 \\
\hline I agree & 0 & 0 & 1 & 9.1 & 1 & 9.1 \\
\hline Absolutely agree & 2 & 18.1 & 1 & 9.1 & 0 & 0 \\
\hline
\end{tabular}

Table 5 Factors effecting in smoking less.

\begin{tabular}{|c|c|c|c|c|c|c|}
\hline & \multicolumn{2}{|c|}{$\begin{array}{c}\text { The ban on advertising for } \\
\text { tobacco products }\end{array}$} & \multicolumn{2}{|c|}{ Warnings on cigarette packs } & \multicolumn{2}{|c|}{ Namely increases in the prices } \\
\hline & $\underline{\mathrm{n}}$ & $\underline{\%}$ & $\underline{\mathrm{n}}$ & $\underline{\%}$ & $\underline{\mathrm{n}}$ & $\underline{\%}$ \\
\hline Absolutely disagree & 11 & 36.6 & 11 & 36.6 & 10 & 33.3 \\
\hline I disagree & 14 & 46.6 & 13 & 43.3 & 17 & 56.6 \\
\hline I have no idea & 1 & 3.3 & 2 & 6.6 & 1 & 3.3 \\
\hline I agree & 2 & 6.6 & 4 & 13.2 & 2 & 6.6 \\
\hline Absolutely agree & 2 & 6.6 & 0 & 0 & 0 & 0 \\
\hline
\end{tabular}

smoke less while $83.2 \%$ was not effected. While $13.2 \%$ of the participants agreed with the idea that warnings on cigarette packs were effective on their decisions to smoke less, $80 \%$ disagreed. $7 \%$ of active smokers thought that price regulations affected their decisions to smoke less, while $90 \%$ of them argued that the increase in cigarette prices was not effective for them to smoke less (Table 5).

Finally, active smokers were asked "Would bans or rewards be more effective if you have to quit smoking immediately?" $28 \%$ of the participants stated that bans could be effective, while the remaining $72 \%$ believed that rewards could be more effective. When they were questioned about the type of rewards they saw fit, they mentioned that rewards like a certain amount of money determined beforehand could be handed to a person selected by drawing lots among people who had proven that they quit smoking, being able to call their doctors even for unrelated reasons whenever they liked, being awarded with a plaque, and talking about their success on television.

\section{Discussion}

Smoking is the most important public health problem in Turkey and accounts for the top reason for preventable deaths. The first legal regulation on this issue in our country was the Article 4207, "Law on Prevention of Hazards of Tobacco Products" adopted in 1996, whose objective was stated to be "to take measures and make the necessary arrangements to protect individuals and future generations from the hazards of tobacco products and from any advertising, promotion or sponsorship promoting the use of tobacco products and ensure that everybody enjoys clean air" and the pursuant amendments, changes, and regulations to the article underlined the necessity to prevent second-hand smoking with a specific focus on protecting both smokers and future generations from the hazards of tobacco products [7]. Although healthcare providers assume an important role for both the initiation and cessation of smoking in a society, the prevalence of smoking within this group is frequently similar to that of the general population in our country $[8,9]$.

Ankara University's Medical School was founded in our country's capital as the first medical school and has a reference hospital which serves patients from all regions in our country. Therefore, the attitudes of healthcare professionals carry a more special significance in that they serve a large population of the society. In our study, however, the rate of smoking 
among this population was found to be rather high at $50.0 \%$.

The results of some studies conducted in our country on the same subject revealed similar results as well. Günay et al., for example, found in their study conducted with 138 healthcare professionals in August 2009 (15 months after the BSCPS) that $51.8 \%$ of the cases were smokers $(47.1 \%$ for males, $58.6 \%$ for females) and $12.1 \%$ were ex-smokers [8]. In another study by Taş et al. conducted in 2005 at a teaching hospital in Istanbul, the authors found that $43.9 \%$ of healthcare professionals were smokers while $15.5 \%$ were ex-smokers [9]. Similarly, Baltaci et al. conducted a study between 2010 and 2011 with 1,233 primary care family physicians and the results of their study revealed that $34.1 \%$ of these physicians were smokers, $14.7 \%$ were ex-smokers, and $51.3 \%$ had never smoked [10].

In a study by Inand 1 et al., conducted with junior medical school undergraduates in our country that covered 1,217 students, it was found that $28.3 \%$ of the individuals in this population were smokers but $47 \%$ of them were exposed to second-hand smoking at home and $42 \%$ in other places within the previous week [11]. In another study conducted with medical school freshmen in our country, it was found out that $23 \%$ of these students were active smokers while $28.3 \%$ of them declared a decrease in their smoking frequency following the SBCPS. The results of this study also revealed that $38 \%$ of the participants believed that the ban on smoking was a violation of individual rights and this rate was significantly higher in the smoker group than the non-smoker group with regards to their ideas on this issue [12].

Vakeflliu et al. investigated the status of smoking of freshmen and fifth year medical school students from Tirana University in Albania and showed that the rate of smoking for male and female freshmen was $34 \%$ and $5 \%$ respectively while this rate went up to $55 \%$ and $34 \%$ for fifth year male and female students respectively [13]. In line with our study's focus on
BSCPS, the results of this study once again underline the fact that medical school students, who are expected to be responsible for public health in the future but presently immersed in intensive workloads, should be prevented from starting smoking.

In another study conducted with freshmen in Tuscany, Italy in 2000 also showed that $30 \%$ of medical students and $43 \%$ of nursing students were smokers while $5 \%$ of medical students and $11.5 \%$ of nursing students were ex-smokers [14].

Similar to the ban in our country, a ban on smoking in closed public spaces and offices went into effect in 2007 in Britain and it was shown that there was a great public support for the ban. In a study on the ban conducted with healthcare professionals investigating their ideas especially about the ban in hospitals, the authors evaluated the ideas of physicians, nurses, allied healthcare staff, who served a population of about 372,000 people at regional hospitals, and medical students on smoking and the ban on smoking. The authors found that the prevalence of smoking among physicians was quite lower than that of the general adult population $(24 \%)$ with $3 \%$. The results of the study also demonstrated that full support for the ban on smoking in closed spaces at hospitals was $68.5 \%$ among physicians, $59.0 \%$ among medical students, $57.8 \%$ among allied healthcare personnel, and $52.0 \%$ among nurses [15]. The fact that the prevalence of smoking among physicians was found to be quite lower than that of the general population in this study assumes a certain significance since it points out to a difference from the one seen in our country. In proportion to the low rate of prevalence of smoking among physicians, it was also physicians who had extended the highest support for the ban on smoking.

In a study conducted with Greek physicians, however, the prevalence of smoking among physicians was found to be quite high (38.6\%) and similar to that of the general population. The results of the same study also showed that $13.8 \%$ of the physicians were ex-smokers [16]. 
Although our study did not include physicians, it all the same is significant when one considers that the attitudes towards smoking of the staff of a university hospital located in the capital of the country can be regarded as models for the society.

Despite the fact that $36 \%$ of the ex-smokers in our study declared that they quit smoking after the BSCPS, none of them mentioned the ban as the reason for their quitting. The most common reasons stated about quitting smoking included health reasons (the fear that their healthy condition might be impaired or the fear that their mild health problems might deteriorate) and this was in turn followed by familial requests, financial reasons, friends' suggestions, the will not to set a bad example for others.

Although legal sanctions and the ban on smoking were not mentioned to be reasons for quitting smoking, the fact that $55 \%$ of our active smoker participants declared that there was a decrease in their amount of smoking after the ban sounds like a positive progress. $37 \%$ of the smokers stated that there was no change in the amount of cigarettes they smoked daily after the BSCPS, while $7 \%$ said that there was an increase. The reasons why there was an increase in the number of cigarettes they smoked were not asked to the smokers but this was interpreted to be related to the will to smoke more before entering into a closed space because of the ban.

Moreover, the fact that $44 \%$ of the smoker participants stated that they were more willing to quit smoking after the SBCPS can be regarded as a positive progress at least in the sense that the ban had directed and encouraged individuals to consider quitting smoking. There was no change, however, for $55 \%$ of the smokers in their will to quit smoking.

In a similar study conducted in Turkey with healthcare professionals including physicians $(\mathrm{n}=523)$ by Türkkanı et al., the authors reported that $85 \%$ of the participants considered the law on the ban on smoking as positive but the level of negative responses increased as the years of smoking and level of addiction went up.
The results of the same study showed that those who had tried to quit smoking previously had a statistically significant positive response to the ban [17].

We did not question whether the ban on smoking directly violated personal rights but only $28 \%$ of our participants stated that such bans could be effective on quitting smoking while the remaining $72 \%$ put forward that rewarding could be more effective in encouraging individuals to quit smoking.

Previous studies conducted in our country have shown that a significant portion of smokers had started smoking before the age of 20. It is also known that the rate of smoking for individuals in high school age in our country varies between $29 \%$ and $50 \%$, while this rate is between $21 \%$ and $48 \%$ for college age [18].

In our study $44 \%$ of current smokers mentioned that they had started smoking between the ages of 15 and 18 as well. It is also another well-known fact that the age of initiation of smoking is an important factor to continue smoking and to being not able to quit $[19,20]$.

Moreover, it is also known that $38 \%$ of mortality cases related to ischemic coronary disease between the ages of 30 and 44 in the world are related to tobacco use. In our country, too, death rates (per 100,000) attributable to tobacco use for those between the ages of 30 and 44 years was 66 and the proportion of deaths attributable to tobacco use for the same age range was $32 \%$ for both sexes [3]. The fact that the negative effects of smoking on health cannot be recognized immediately with the initiation of smoking but that these negative effects of the habit of smoking acquired during adolescence and/or younger years can only be realized later in life underline the need to prevent adolescents and young individuals from starting smoking in the first place. Within this context, the significance of the objective of the ban on smoking in closed public spaces to protect future generations from the hazardous effects of cigarettes and other tobacco products is realized once again [20].

The reasons of initiation of smoking have been reported to be similar by many studies in literature. 
Curiosity to know what it is, the will to try something new, having a smoker friend and the will to be accepted by friends, reactionary behavior, imitation, environmental factors, stress or a problem, and the fact that it was banned have been reported among the reasons for the initiation of smoking [20]. It is also known that social factors play a more significant role in individual's attitudes towards smoking rather than personal factors [4]. In our study, too, the most common reason among the reasons for the initiation of smoking was stated to be "peer influence" with a high rate of $56 \%$. This was followed by curiosity, imitation, being under stress. As is seen in our study and in many other similar studies, "friends" and circle of friends assume a very important role in the initiation of smoking especially in an individual's younger years [21].

The most frequent reasons for the cessation of smoking offered in our study were health issues with $73 \%$ followed by the demands of families with $36 \%$. Friends' suggestions lagged behind with $18 \%$.

$55 \%$ of our cases stated that there was a decrease in the number of cigarettes they smoked following the ban on smoking in closed public spaces, while $44 \%$ said they became more willing to quit smoking. In a similar study conducted in our country with college students, the authors reported that $17 \%$ of these undergraduates declared a decrease in the number of cigarettes they smoked, $73 \%$ mentioned no change, and 10\% stated an increase. Following the law's going into effect, the rate of those who violated the ban on smoking in closed public spaces increased significantly. The results of the same study also revealed that $64 \%$ of the undergraduates stated that they considered quitting smoking following the ban [22].

In another similar study conducted in our country, the authors reported that $7.4 \%$ of the participants stated that there was a decrease in the number of cigarettes they smoked after the ban, $75 \%$ declared an increase, and $27 \%$ mentioned no changes [23].

A great majority of the participants covered by our study put forward that the ban on advertising of tobacco products and the warnings on cigarette packs had no effect on the issue of quitting smoking (82\% and $73 \%$ respectively).

The results of a study by Baykan et al. revealed that non-smoker students offered statistically significant positive responses in comparison to smoker students to questions related to warnings on cigarette packs about the hazards of smoking, the ban on advertising of tobacco products, and the ban on smoking in closed public spaces [12]. This situation underlines the necessity to protect non-smokers from the hazards of second-hand smoking highlighting the significance of this ban.

Most of the participants in our study stated that increases in cigarette prices would not affect individuals' decisions on quitting or decreasing the number of cigarettes they smoked. A similar result was also shown by a study conducted in our country by Özşahin et al. and those who had quit smoking did not cite high cigarette prices as a reason effective in quitting smoking [24].

\section{Conclusions}

The results of our study revealed that BSCPS had no effect on smokers' decisions about quitting smoking. The fact, however, that it is known that the objective of this ban was to prevent second-hand smoking with a specific focus on protecting both smokers and future generations from the health hazards of tobacco products and that it would be preventive in the initiation of smoking in the long run proves to be of utmost importance in the careful observation of the ban.

Social leadership and role model characteristics of healthcare professionals should be taken into consideration and the habit of smoking specifically within this group should be handled as a disease, and medical approaches including behavioral therapy, intensive motivational support, and pharmacological treatment should be given the necessary significance they deserve. 


\section{References}

[1] Feigl, A. B., Salomon, J. A., Danaei, G., Ding, E. L., and Calvo, E. 2015. "Teenage Smoking Behaviour following a High-school Smoking Ban in Chile: Interrupted Time-series Analysis." Bull World Health Organ 93 (7): 468-75.

[2] Novotny, T. E., Bialous, S. A., Burt, S., Curtis, C., Costa, V. L., and Iqtidar, S. U., et al. 2015. "The Environmental and Health Impacts of Tobacco Agriculture, Cigarette Manufacture and Consumption." Bull World Health Organ 93 (12): 877-80.

[3] WHO Report on the Global Tobacco Epidemic, 2015. Available from: http://www.who.int/tobacco/global_report/2015/en/.

[4] Bilir, N. 2009. "Level of Tobacco Control in Turkey." Turk. Thorac. J. 10 (1): 31-4.

[5] Erbaycu, A. E., Aksel, N., Çakan, A., and Özsöz, A. 2004. "Smoking Habit of Health Professionals in İzmir City." Turk. Thorac. J. 5 (1): 6-12.

[6] Yüksel, E. G. 2000. "Sigaraya başlamanın önlenmesinde hekimin rolü. In: Özyardımcı N.ed. Sigara ve Sağlık." Bursa: 429.

[7] Tütün mamullerinin zararlarının önlenmesine dair kanun; 1996. Available from: www.resmigazete.gov.tr/arsiv/22829.pdf.

[8] Günay, E., Şimşek, Z., Kutucularoğlu, G., and Metinyurt, G. 2010. "Smoking Prevalence, Nicotine Dependence and Effects of Low Cost Cigarette Sale among Military Healthcare Personal in Turkish Republic of Northern Cyprus." Tuberk Toraks 58 (4): 393-400.

[9] Taş, D., Okutan, O., Kaya, H., Kartaloğlu, Z., and Bozkanat, E. 2009. "Smoking Prevalence among Military Healthcare Personel in İstanbul." Turk. Thorac. J. 10 (1): 15-9.

[10] Baltacı, D., Bahçebaşı, T., Aydın, L. Y., Öztürk, S., Set, T., and Eroz, R., et al. 2014. "Evaluation of Smoking Habits among Turkish Family Physicians." Toxicol. Ind. Health 30 (1): 3-11.

[11] Inandi, T., Caman, K., Aydin, N., Onal., A. E., Kaypmaz, A., and Turhan, E., et al. 2013. "Global Health Professions Student Survey-Turkey: Second-hand Smoke Exposure and Opinions of Medical Students on Anti-tobacco Law." Cent Eur. J. Public Health 21 (3): 134-9.

[12] Baykan, Z., and Naçar, M. 2014. "Smoking Prevalence and Views about Tobacco Law in Students of Medical School." Dicle Med. J. 41 (3): 483-90.

[13] Vakeflliu, Y., Argjiri, D., Peposhi, I., Agron, S., and Melani, A. S. 2002. "Tobacco Smoking Habits, Beliefs, and Attitudes among Medical Students in Tirana." Albania Prev. Med. 34 (3): 370-3.

[14] Melani, A. S., Verponziani, W., Boccoli, E., Trianni, G. L., Federici, A., and Amerini, R. 2000. "Tobacco Smoking Habits, Attitudes and Beliefs among Nurse and Medical Students in Tuscany.” Eur. J. Epidemiol. 16 (7): 607-11.

[15] Lewis, K. E., Shin, D., and Davies, G. 2011. "Smoking Habits and Attitudes toward Tobacco Bans among United Kingdom Hospital Staff and Students." Int. J. Tuberc. Lung Dis. 15 (8): 1122-6.

[16] Sotiropoulos, A., Gikas, A., and Spanou, E., et al. 2007. "Smoking Habits and Associated Factors among Greek Physicians." Public Health 15 (8): 333-40.

[17] Türkkanı, M. H., Aydın, L. Y., and Özdemir, T. 2014. "Alternations in Smoking Habits of Active Smoker Health Care Professionals after the Law on Prevention of Harmful Effects of Tobacco and Tobacco Products." Eurasian J. Pulmonol. 16 (3): 175-9.

[18] Özcebe, H. 2008. Gençler ve sigara. Sağlık Bakanlığ1 Yayın No: 731. Klasmat Matbaacılık Ankara.

[19] Özcebe, H., Doğan, B. G., İnal, E., Haznedaroğlu, D., and Bertan, M. 2014. "Smoking Habits and the Related Sociodemographic Characteristics in University Students." Turk Thorac. J. 15 (2): 42-8.

[20] Khuder, S. A., Dayal, H. H., and Mutki, A. B. 1999. "Age at Smoking Onset and Its Effect on Smoking Cessation." Addict Behav. 24 (5): 673-7.

[21] Okoli, C., Greaves, L., and Fagyas, V. 2013. "Sex Differences in Smoking Initiation among Children and Adolescents." Public Health 127 (1): 3-10.

[22] Topçu, B., Ünsal, C., Gazeloğlu, C., and Aktaş, S. 2014. "The Effect of Indoor Smoking Restriction Law on Soking Habits of University Students." Int. J. Basic Clin. Med. 2 (1): 24-31.

[23] Doğan, Ş. H., Naz, I., and Aksel, N. 2015. "Smoking Habits in Hospital Staff: Is there Effect of Psychological Problems?" İzmir Göğüs Hastanesi Dergisi 29 (2): 85-93.

[24] Özşahin, K., Ünsal, A., Erdoğan, F., Gereklioğlu, Ç., Bakar, C., and Tokalak, I. 2007. "Factors Effective On Smoking Cessation: A Study on Family Practice Patients." TAF Prev. Med. Bull 6 (3): 181-6. 